\footnotetext{
Teresa Méndez-Faith

Esta investigadora paraguayo-estadounidense es profesora del St. Anselms College, universidad católica del noreste de los Estados Unidos. Doctorada en Filosofía y Letras por la Universidad de Michigan (Ann Arbor) en 1979, es una de las investigadoras que mayor empeño ha putesto en la regulación y el ordenamiento de datos y obras de la literatura paraguaya, cuyos frutos son su Breve diccionario de la literatura paraguaya, del cual prepara su tercera edición y es obra indispensable consulta y referencia para el acercamiento al tema, junto a sus antologías Narrativa paraguaya de ayer $y$ de hoy, Poesia paraguaya de ayer y de hoy, y Teatro paraguayo de ayer y de hoy. Su tesis doctoral se editó posteriormente con el título de Paraguay: novela y exilio. Entre otros numerosos trabajos sobre literatura de Hispanoamérica, fue la autora de las entradas de los autores paraguayos incluidos en el Diccionario de la Literatura Española e Hispanoamericana, dirigido por Ricardo Gullón, publicado en 1993.
}

1

Según Efraím Cardozo, en su Breve historia del Paraguay (Buenos Aires: Eudeba, 1965). Agrega él que de 1.300 .000 paraguayos vivos a principios de la guerra, sólo quedaron 300.000 al final, en su mayoría mujeres y niños.

Núcleos temáticos recurrentes en la narrativa paraguaya del último cuarto de siglo

TERESA MÉNDEZ-FAIT'H

\title{
NÚCLEOS TEMÁTICOS RECURRENTES EN LA NARRATIVA PARAGUAYA DEL ÚlTIMO CUARTO DE SIGLO
}

\author{
TERESA MÉNDEZ-FAITH
}

De toda Latinoamérica, Paraguay es, probablemente, el país cuya producción literaria se ha visto más afectada por los aconteceres histórico-políticos de sus casi dos siglos de vida independiente. Es la única nación del continente que se inició como tal con una dictadura. En efecto, allí se instaló el régimen absolutista del primer gran dictador hispanoamericano, el Dr. José Gaspar Rodríguez de Francia, conocido como «El Supremo», quien aisló al Paraguay del resto del mundo y lo dominó como gobernante absoluto desde 1814 hasta su muerte en 1840. Le sucedió don Carlos Antonio López cuyo gobierno, también autoritario aunque constitucional, duró hasta 1862. Le siguió en el cargo su hijo, el Mariscal Francisco Solano López, una de las figuras más controversiales de la historia paraguaya. «Traidor a la patria» para unos y «héroe nacional máximo» para otros, durante su corto gobierno, Paraguay peleó y perdió la Guerra de la Triple Alianza (1864-1870), donde se enfrentó, quijotescamente, contra las fuerzas aliadas de Brasil, Argentina y Uruguay, sufriendo en el proceso la pérdida de más del $75 \%$ de su población ${ }^{1}$. A esa hecatombe nacional siguieron décadas de anarquía, golpes de estado, y se repitieron los regímenes dictatoriales y autoritarios hasta el otro gran enfrentamiento internacional, la Guerra del Chaco con Bolivia (1932-1935) que, a pesar del triunfo paraguayo, dejó al país humana y económicamente devastado. Un par de años de paz (1936-1937) y después otra vez la anarquía, gobiernos provisionales despóticos, una sangrienta Guerra Civil (1947), otro breve espacio de relativa tranquilidad y la instalación en el poder del General Alfredo Stroessner (en 1954) cuya dictadura, la más represiva y la más larga de los anales paraguayos, culminó en el golpe de estado del 3 de febrero de 1989. Desde entonces hasta el presente, trece años de un difícil proceso de transición hacia la democracia y un nuevo milenio de esperanzas para que dicho proceso tenga un final feliz...

He aquí, resumidos en un párrafo largo, los vaivenes y vicisitudes de la historia del $\mathrm{Pa}$ raguay desde sus inicios como nación hasta principios del siglo XXI, historia enmarcada entre dos largas dictaduras, la del Dr. Francia (1814-1840) y la del Gral. Stroessner (19541989), y poco más de una década de ensayos y tentativas de democratización, hasta ahora muy frágiles. He aquí también los datos necesarios que explican, aunque sea en parte, el porqué de la escasez literaria paraguaya a menudo mencionada por estudiosos e historiadores de nuestra literatura y en particular por quienes la tratan de comparar y contrastar con otras literaturas hispanoamericanas.

Antes de tratar de aislar los núcleos temáticos recurrentes en la narrativa paraguaya del último cuarto de siglo, incluyendo aquí novelas y cuentos publicados a partir de 1974, dentro y fuera del país, es importante describir, a grandes rasgos, la situación de dicha narrativa antes de los años setenta. En particular, es necesario señalar algunas consecuencias del trágico derrotero histórico-político arriba deli- 
neado, irónicamente muy positivas para la narrativa paraguaya actual.

En primer lugar, y en términos generales, la narrativa ha sido el género menos prolífico de las letras paraguayas y el más afectado por el contexto histórico-político nacional. Hasta mediados del siglo XX predominó el ensayo histórico y en la escasa producción narrativa del período tendieron a prevalecer, como en el ensayo, las corrientes romántico-nacionalistas de exaltación del pasado y de afirmación de los valores espirituales del pueblo paraguayo, heroico sobreviviente de la catástrofe de la Guerra de la Triple Alianza2. Posteriormente, la Guerra del Chaco (1932-1935) que fue, según Andrew Nickson, «the bloodiest and most prolonged war in twentieth century Latin America...» ${ }^{3}$, tuvo, no obstante, consecuencias positivas en el plano literario al promover una toma de conciencia de la realidad nacional y la incorporación de temas significativos (la guerra, los problemas del agro y de los yerbales, la persecución política, el exilio, etc.) en la narrativa posterior ${ }^{4}$.

La Revolución Civil de 1947 que inició un proceso migratorio masivo, hasta hoy el más largo de su historia, y la dictadura de Stroessner que lo continuó durante tres décadas y media, llevaron al exilio - entre los miles y miles de paraguayos que se vieron forzados a dejar su patria - a un número muy grande de la intelectualidad del país. Muchos escritores, artistas, músicos, profesionales, etc., tuvieron que dejar su tierra natal para sobrevivir, separándose forzosamente de amigos y parientes. Estas dos tragedias histórico-políticas que durante casi medio siglo dividieron a la familia paraguaya, con consecuencias funestas para el país, tuvieron, sin embargo, un impacto muy positivo en el desarrollo y actualización de la narrativa paraguaya contemporánea. En efecto, una de las consecuencias culturales más significativas de dicho éxodo intelectual fue el quehacer literario de algunos escritores integrantes de esa emigración masiva del 47, como Augusto Roa Bastos, y de otros, como Gabriel Casaccia, que habiendo dejado el país antes, empezaron a publicar sus cuentos y novelas en Buenos Aires. Iniciaron así estos dos escritores (a los que se agregaron después varios más como Rubén Bareiro Saguier, Carlos Garcete, Lincoln Silva, Rodrigo Díaz-Pérez, etc.) la importante vertiente de la narrativa paraguaya del exilio cuyo «corpus» cuenta en su haber con un gran número de obras publicadas pero cuya vigencia caduca, termina, lógicamente, con la caída de Stroessner en 1989, al poder volver todos ellos, sin miedo ya a represalias, a su tierra natal. Y hasta la fecha, casi todos han vuelto...

Es importante enfatizar, sin embargo, que el papel de la escritura del exilio fue fundamental y clave en la renovación de la narrativa paraguaya contemporánea. Pero es igualmente importante señalar el hecho de que las obras aparecidas fuera del país inauguran e incorporan una serie de temas prácticamente ausentes en la narrativa coetánea de dentro. En este trabajo se identifican algunos núcleos temáticos que inicialmente aparecen de manera recurrente en la producción del exilio, pero que reaparecen después, también recurrentemente, en la narrativa concebida y publicada intrafronteras. Con respecto a estas dos vertientes, la de dentro y la de fuera, hay que recordar que la narrativa paraguaya recién empezó a adquirir distinción y atención internacional en la década del 50, con la aparición en Buenos Aires de tres obras - La Babosa (novela, 1952) de Gabriel Casaccia, Follaje en los ojos (novela, 1952) de José María Rivarola Matto y El trueno entre las hojas (1953), la primera colección de cuentos de Augusto Roa Bastos- que rompieron con las tendencias narcisistas y mitificadoras prevalecientes y reincorporaron a la ficción el realismo crítico inaugurado por Rafael Barrett a principios del siglo XX pero prácticamente ausente en la narrativa publicada hasta entonces dentro del país.

En efecto, es también en la producción del exilio de los años 50, 60 y 70 donde se detectan por primera vez ciertos temas o núcleos temáticos entonces apenas soslayados o totalmente ausentes en la narrativa de dentro - como los relacionados con la crítica y denuncia de la realidad socio-política, el exilio, la reinterpretación o revisión de la historia, la dictadura... - pero que sí constituirán temática recurrente en la narrativa posterior, en particular de las últimas dos décadas del siglo $\mathrm{XX}$. Teniendo en cuenta el contexto socio-político, las tensiones, represiones y miedos vigentes en el Paraguay de Stroessner, es también fácil deducir que las obras actualmente

\section{NOVELA} MAROHALEWHOPA LA OUEWA II

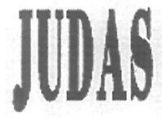

Cuarta edición DITORIAL COMUNEROS

a quema de Judas. Portada.

2

Dentro de esa línea tradicionalista, iniciada por el argentino Martín de Goycoechea Menéndez - glorificador de la Guerra Grande y mitificador de la literatura nacional- habría que mencionar las obras histórico-costumbristas de Natalicio González, Teresa Lamas de Rodríguez Alcalá, Concepción Leyes de Chaves y Carlos Zubizarreta.

3

Ver su Hisiorical Dictionary of Paraguay, 2nd. ed. (Metuchen, N.J. \& London: The Scarecrow Press, Inc., 1993), pág. 118. Indica él también allí que "Some 60,000 Bolivians and 30,000 Paraguayans lost their lives, many from the effects of the harsh climatic conditions of the war-zone».

4

Ejemplifican dicha renovación temática: Cruces de quebracho (1934) de Arnaldo Valdovinos, Ocho hombres (1934) de José Santiago Villarejo, ambas inspiradas en la guerra del Chaco, y especialmente El guajhú (1938) de Gabriel Casaccia, colección de cuentos donde su autor da el golpe definitivo a la visión literaria idealizada y romántica, totalmente falsa del campesino paraguayo.

Núcleos temáticos recurrentes en la narrativa paraguaya del último cuarto de siglo

TERESA MÉNDEZ-FAITH 


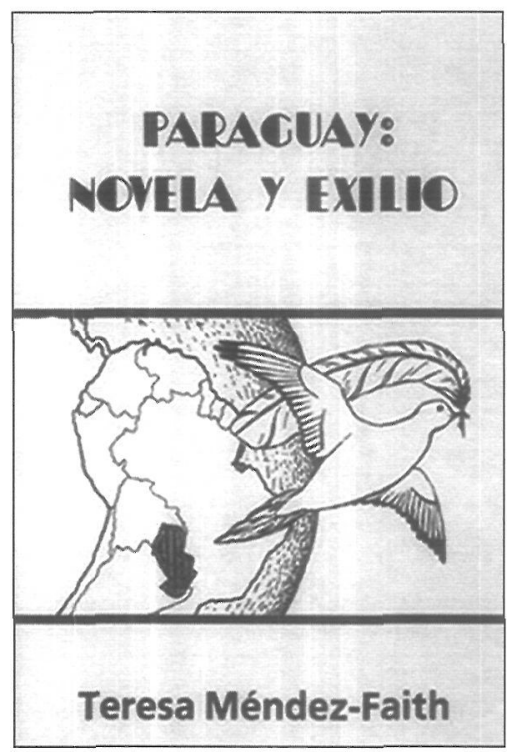

Paraguay: novela y exilio. Portada.

más conocidas hayan sido concebidas y publicadas en el exilio. Y esto por una razón muy sencilla: lejos del miedo, de las amenzas y posibles represalias, censuras y autocensuras asociadas con su país, a los escritores exiliados les fue posible expresarse libremente y desarrollar sin trabas una narrativa artísticamente elaborada, a tono con el momento histórico presente y de contenido socio-político significativo. Para los escritores que quedaron intrafronteras, escribir se convertía en un acto subversivo: contra el gobierno, contra la historia oficial, contra los escasos mecanismos de publicación y divulgación de la obra literaria. De ahí que fuera en los textos de esos expatriados ya antes mencionados - Rubén Bareiro

5

Es interesante constatar que mientras la narrativa concebida y publicada fuera del país produce varios iextos con el tema del exilio, en esos años hay solamente una novela publicada en 1965 en Paraguay: Imágenes sin tierra de José-Luis Appleyard.

6

Ver José Vicente Peiró Barco, esfudio introductorio a Mancuello y la perdiz (Madrid: Ediciones Cátedra, 1996) de Carlos Villagra Marsal.

Núcleos temáticos recurrentes en la narrativa paraguaya del último cuarto de siglo

TERESA MÉNDEZ-FAITH
Saguier, Gabriel Casaccia, Rodrigo Díaz-Pérez, Carlos Garcete, Augusto Roa Bastos, Lincoln Silva y algunos más- donde se expresaron, inicialmente, tanto el planteamiento más directo como el reflejo más fiel de la problemática nacional de esas tres décadas y media (1954-1989) de dictadura stronista.

Gabriel Casaccia, iniciador de la narrativa paraguaya contemporánea, recupera de manera crítica varias décadas de descomposición moral y corrupción política en tres novelas: La Babosa, La llaga (1963) y Los herederos (1975), y dedica Los exiliados (1966) a tocar el tema del exilio político, prácticamente inexplorado en la narrativa intrafronteras 5 . Augusto Roa Bastos, Premio Cervantes 1989 , examina el presente y el pasado nacionales a lo largo de coordenadas histórico-políticas en Hijo de hombre (1960) - novela del dolor paraguayo- y en Yo el Supremo (1974), su segunda y más famosa novela, narrada desde la ubicua perspectiva del doctor José Gaspar Rodríguez de Francia, primer dictador paraguayo y una de las figuras más controversiales de la historia nacional. En ambos autores, el tema de la obsesión por el pasado permea prácticamente todas sus obras: en Casaccia, el pasado penetra la narración de manera indirecta e implícita, mientras que en Roa el pasado es un discurso constante, directo y explícito.

La dictadura, tema de difícil incorporación en la narrativa interna, está implícita o explícita en el miedo que atormenta a tantos personajes de las obras del exilio. Y se hace directa en su realidad de cárceles, torturas y persecuciones en varios cuentos de Rubén Bareiro Saguier -incluidos en Ojo por diente (1973) y en El séptimo pétalo del viento (1984) - y de Rodrigo Díaz-Pérez - contenidos en Entrevista (1978), en Hace tiempo... mañana (1989) y en Los dias amazónicos (1995) - como también en las dos novelas de Lincoln Silva: Rebelión después (1970) y General General (1975). Productos del destierro, aunque ya de fines de los 80 , son también dos obras inspiradas en la problemática de la dictadura: El collar sobre el río (cuentos) de Carlos Garcete y El invierno de Gunter (novela) de Juan Manuel Marcos, ambas publicadas en 1987. Como bien lo señala José Vicente Peiró en uno de sus trabajos sobre nuestra narrativa: «El año 1987 resulta clave porque se difunden tres novelas importantes que renuevan la narrativa paraguaya: Caballero, de Guido Rodríguez Alcalá (editada en Paraguay en 1986, y en Buenos Aires al año siguiente); El invierno de Gunter, de Juan Manuel Marcos, y La niña que perdí en el circo, de Raquel Saguier ${ }^{6} . »$ Comenta Peiró, en el mismo trabajo, que Caballero «representa la desmitificación de la sacralizada historia nacional», El invierno... «mezcla argumentos en una misma narración principal» y en La ni-

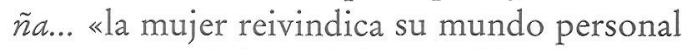
en una sociedad que la ha considerado como un ser marginal, con la ironía y la ingenuidad de la mirada infantil». Coincidimos con nuestro colega y amigo español que lo significativo de la aparición y difusión de estas tres obras en el mismo año es que "Las tres abandonan el maniqueísmo y los tópicos localistas, e incluso reinterpretan la historia y la realidad de las rígidas estructuras sociales del Paraguay tradicional» (de la misma introducción, pág. 29).

Teniendo en cuenta la propuesta y en realidad el eje de este trabajo -i.e., que gran parte de la temática recurrente en la narrativa de los últimos 25 años ya fueron captados/expresados en la narrativa del exilio de los años 50,60 y $70-$ es necesario puntualizar aquí que los temas recurrentes en las tres obras que acabamos de mencionar (aparecidas a fines del stronismo, en 1987), y en particular los relacionados con la reinterpretación o revisión crítica de la historia, ya están presentes y recurrentes en los cuentos y novelas de Casac- 
cia, Roa Bastos, Bareiro-Saguier, Lincoln Silva..., publicados en el exilio, antes de 1975.

Si empezamos con el núcleo temático en torno a la crítica y/o denuncia de la realidad socio-política nacional, debemos recordar que su expresión inicial se da en la ficción de Casaccia y Roa de los años 50 y 60: La Babosa (1952), La llaga (1963), Los exiliados (1966); El trueno entre las bojas (1953), Hijo de bombre (1960)... Este motivo se vuelve recurrente en varias obras del último cuarto de siglo, publicadas tanto dentro como fuera del país y escritas por escritores del exilio o de intrafronteras. En particular, está presente en novelas y cuentos de estos mismos autores, aparecidos posteriormente: Los herederos de Casaccia y un gran número de relatos de Roa incluidos en El baldío, Los pies sobre el agua, Madera quemada, Moriencia y otros, como también en la narrativa de Rubén Bareiro-Saguier, Carlos Garcete y Rodrigo Díaz-Pérez, con publicaciones posteriores a su retorno del exilio.

La misma temática de captación crítica de la realidad socio-política nacional, de denuncia de la violencia y la opresión, empieza a aparecer de manera recurrente en obras publicadas intrafronteras a partir de 1975. Tal es el caso de varios cuentos incluidos en El contador de cuentos (1980) de Jesús Ruiz Nestosa, Angola y otros cuentos de Helio Vera (1984), La seca y otros cuentos (1986) y Por el ojo de la cerradura (1993) de Renée Ferrer, Cuentos decentes (1987), Curuzú cadete (1989) y Cuentos (1993) de Guido Rodríguez Alcalá y Los hombres del sur (1987) de Catalo Bogado, Tierra mansa y otros cuentos (1987) de Lucy Mendonça, Papeles de Lucy-fer (1992) y En el país de las mujeres (1995) de Jorge Canese, Memoria sin tiempo (1992) de Maybell Lebrón, La víspera y el día (1992) y Cuentos de tierra caliente (1999) de Dirma Pardo Carugati, Ora pro nobis (1993) de Neida Bonnet de Mendonça, Entre la cumbre y el abismo (1995) de Susana Riquelme de Bisso, Relatorios (1995) de Gilberto Ramírez Santacruz, y en varias obras más recientes. Esta mirada crítica al entorno de la realidad socio-política nacional también está captada en algunas novelas del último cuarto de siglo: entre ellas, en Función patronal (1980) de Alcibiades González Delvalle, Los nudos del silencio (1988) de Renée Ferrer, La vera historia de Purificación (1989) y Esta zanja está ocupada (1993) de Raquel Saguier, El destino, el barro y la coneja
(1990) y Donde ladrón no Llega (1996) de Luis Hernáez, Diálogos prohibidos $y$ circulares (1995) de Jesús Ruiz Nestosa, para dar un número representativo de ejemplos.

En contraste con la temática de captación crítica de la realidad nacional en la ficción posterior a 1975 , el tema del exilio aparece ocasionalmente, aunque no de manera recurrente, en la narrativa de dentro (intrafronteras). Sin embargo, sigue siendo tematizado en las obras de los escritores asociados con el exilio (Roa Bastos, Bareiro Saguier, Díaz-Pérez...), escritas y publicadas en los últimos 25 años.

Otro núcleo temático inicialmente reflejado en la narrativa del exilio y que resulta bastante recurrente en la que aparece intrafronteras, durante el último cuarto de siglo, es el relacionado con la reinterpretación, re-creación, revisión crítica de la historia o de algún personaje específico de dicha historia. Si en 1960 Hijo de bombre pasa revista y recrea críticamente ciertos momentos de la historia nacional que van desde la época del Dr. Francia hasta los albores de la Guerra Civil del 47, incluyendo la agonía de la sed en la Guerra del Chaco, y si en Yo el Supremo, de 1974, es el supremo dictador y su período los que están en tela de juicio, revisados, re-creados y enjuiciados por las múltiples voces y documentos históricos reales y ficticios, son muchos los textos que desde fines de la década del 70 y especialmente a partir de los años 80 incorporan dichos núcleos temáticos al discurso narrativo. Se cuestiona y re-construye o re-interpreta la historia en Diagonal de sangre (1986) - novela que explora el contexto socio-económico-político en que se desarrolló la Guerra de la Triple Alianza - y en La isla sin mar (1987) de Juan Bautista Rivarola Matto, en Donde ladrón no llega (1996) de Luis Hernáez, donde se recrea la época de los jesuitas en 1767, el año de su expulsión, y en Vagos sin tierra (1999) de Renée Ferrer, centrada en la historia de una familia del siglo XVIII que emigra hacia el norte para colonizar unas tierras fronterizas con el imperio lusitano y aún dominadas por los indígenas. Se reconstruye un derrotero histórico personal en las novelas
Núcleos temáticos recurrentes en la narrativa paraguaya del último cuarto de siglo TERESA MÉNDEZ-FAITH 
Núcleos temáticos recurrentes en la narrativa paraguaya del último cuarto de siglo

TERESA MÉNDEZ-FAITH
Caballero (1986) y Caballero Rey (1989) de Guido Rodríguez Alcalá, dos versiones-revisiones de la figura del General Bernardino Caballero, héroe de la Guerra de la Triple Alianza, desmitificación de la carrera militar del personaje la primera obra y del hombre político la segunda, ambas cubriendo un período histórico que va de 1871 a 1887; y también en El fiscal (1993) de Roa Bastos, para mencionar media docena de novelas significativas.

El núcleo de temas que incluye el de la dictadura y el de la figura del dictador, igualmente estrenados en Yo el Supremo, está también muy visible en la narrativa de las últimas dos décadas. Si bien la figura de Stroessner está presente de manera implícita en Yo el Supremo (en los anacronismos referentes a la firma del tratado de Itaipú en 1973, por ejemplo), está explícitamente captado, revisado, criticado y denunciado en las novelas $\mathrm{Cel}$ da 12 (1991) de Moncho Azuaga, y en El rector (1991) de Guido Rodríguez Alcalá. También la dictadura está presente en el testimonio de la violencia y del terror que se ven expresados en muchos de los cuentos de Guido Rodríguez Alcalá (Cuentos decentes, Curuzú cadete, Cuentos), en las últimas novelas de Roa Bastos (El fiscal, Contravida y Madama Sui), en Tacumbú, infierno y gloria (1991) de Santiago Trías Coll, en Historia(s) de Babel (1992) de Lito Pessolani y en varias otras más. Igualmente significativas porque exploran en profundidad ciertas llagas dolorosas de la realidad paraguaya son obras que han ido apareciendo en los últimos años 15 años, entre ellas: Medio siglo de agonia (1994) de Santiago Dimas Aranda; Stroessner roto (1989) de Jorge Canese; Los nudos del silencio (1988) y Vagos sin tierra (1999) de Renée Ferrer; El caballo del comisario (1996) de Carlos Garcete; Demasiada bistoria (1988) de Sara Karlik, Diálogos probibidos y circulares (1995) de Jesús Ruiz Nestosa; Sin testigos (1987) de Roberto Thompson Molinas; y En busca del bueso perdido: Tratado de paraguayología (1990) y Angola y otros cuentos (1984 y 1994, 2a. ed. aumentada) de Helio Vera, prácticamente todas premiadas o finalistas en concursos nacionales de narrativa. En este grupo de obras la crítica a menudo se vuelve denuncia condenatoria del régimen dictatorial represivo y asfixiante de más de tres décadas.

Un aspecto interesante y significativo de la producción narrativa de las últimas dos déca- das - que además agrega otro par de núcleos recurrentes a la gama temática de la narrativa paraguaya actual - es la aparición de un alto porcentaje de voces femeninas en el panorama literario de este período más reciente. Más que en ninguna época anterior, dichas voces se manifiestan con gran fuerza y continuidad, y sus obras reflejan, temática y estructuralmente, preocupaciones y estilos diversos, a tono con la narrativa latinoamericana del último cuarto de siglo. Temas relacionados con la expresión de lo íntimo, del mundo interior, con la transgresión de la norma, la ruptura de tabúes, con la toma de conciencia de la realidad desde una perspectiva femenina, son motivos que amplian los núcleos temáticos recurrentes existentes hasta el momento y que coinciden con la irrupción de la mujer en el panorama narrativo del último cuarto de siglo.

Además de las obras de Renée Ferrer, ya antes mencionadas, hay que incluir en este grupo las de varias otras que se estrenan como narradoras en este período o que reflejan dichos temas (o algunos de ellos) en sus obras, entre ellas: Golpe de luz (novela, 1983) y Ora pro nobis (cuentos, 1993) de Neida Bonnet de Mendonça; las novelas de Raquel Saguier ya indicadas (La niña que perdí en el circo, La vera bistoria de Purificación y Esta zanja está ocupada) y La posta del placer (1999); La oscuridad de afuera (cuentos, 1987) y Presentes anteriores (1996) de Sara Karlik, y Tierra mansa y otros cuentos (1987) de Lucy Mendonça. Una variedad temática singular que se manifiesta en algunos cuentos del grupo más joven de escritoras (Delfina Acosta, Lita Pérez Cáceres, Milia Gayoso, Chiquita Barreto, Nila López, Amanda y Mabel Pedrozo), aunque todavía no se la podría calificar de recurrente, es el tema erótico que está presente en muchos cuentos de Con el alma en la piel (1994) y Delirios y certezas (1995) de Chiquita Barreto.

Otro núcleo temático importante que aporta la escritura femenina en estos últimos años es el de carácter ecológico y está representado especialmente por los cuentos ecológicos incluidos en $E \cos$ de monte $y$ arena (1992) de Luisa Moreno de Gabaglio y los relatos que integran Desde el encendido corazón del monte (1994) de Renée Ferrer. Tampoco aquí podemos hablar todavía de una recurrencia temática pero sí de un nuevo aporte temático a la narrativa paraguaya actual. 
Para concluir esta rápida revisión de los núcleos temáticos recurrentes en la narrativa paraguaya del último cuarto de siglo, llaman la atención un par de cosas: en primer lugar, que los temas que recurren con más frecuencia en estas obras, tanto de escritores como de escritoras, son los mismos o muy relacionados con los núcleos temáticos ya reflejados en la narrativa del exilio de los años 50, 60 y 70, también omnipresentes en la narrativa hispanoamericana del último medio siglo en autores consagrados y de la fama de Gabriel García Márquez, Mario Vargas Llosa, José Donoso, Julio Cortázar, Juan Rulfo, Alejo Carpentier, Carlos Fuentes o Mario Benedetti. Y en segundo término, que la irrupción de la escritura femenina en Paraguay a partir de la década de los 80 sea paralela, incluso en aportes temáticos, a la que se produce en el resto de los países de Hispanoamérica con escritoras también muy conocidas como Claribel Alegría (El Salvador),
Isabel Allende y Marcela Serrano (Chile), Laura Esquivel, Angeles Mastretta y Elena Poniatowska (México), Rosario Ferré (Puerto Rico), Luisa Valenzuela (Argentina), Carmen Naranjo (Costa Rica), Cristina Peri Rossi (Uruguay) y otras. Llama la atención, en fin, la gran productividad narrativa actual pero al mismo tiempo ello es también consecuencia lógica de que las coordenadas histórico-políticas que condicionaron dicha producción por tanto tiempo, e impidieron o limitaron la producción narrativa hasta 1989 , hayan finalmente desaparecido y existe hoy libertad y más oportunidades para la tarea creativa de los escritores y escritoras de Paraguay. Celebro profundamente que en el último cuarto de siglo nuestro país haya dado muestras de tanta energía y productividad creativa ya que esto es augurio de un sólido «corpus» narrativo con una variedad temática «extra-ordinaria» para este nuevo siglo y milenio... 